\title{
ANALYSIS OF HEAT TRANSFER IN STEEL BILLETS DURING TRANSPORT
}

\author{
K. N. Cançado ${ }^{\mathrm{a}}$, \\ L. Machado ${ }^{\mathrm{a}}$, \\ and L. N. Soares ${ }^{b}$ \\ ABSTRACT \\ During the seamless steel tubes manufacturing process, the temperature \\ decrease between the exit of the furnace and the rolling mill entrance is \\ determinant factor in the rolling process and the quality of the tube. This \\ study aims to model the cooling of the billets during transport in order to \\ evaluate the minimum temperature required for the billet leaves the furnace \\ and also the maximum transport time without compromising the rolling \\ process, allowing a better setup of equipment and reducing the production \\ costs. The cooling profile was determined numerically through energy \\ balances performed on the billet and the results obtained were compared \\ with real values of temperature measurements by thermocouples installed \\ on the billet. Measurements with thermocouples were conducted in billets \\ of 270,230 and $180 \mathrm{~mm}$ diameter. The error relative to the real values for \\ all cases was below than $2.5 \%$ and the model is considered validated to use. \\ kancado@hotmail.com.br \\ Belo Horizonte, MG, Brasil \\ CEP 30640-010 \\ Received: April 14, 2018 \\ Revised: May 09, 2018 \\ Accepted: May 30, 2018 \\ Keywords: cooling, transport, rolling mill, heat transfer, cost
}

\section{NOMENCLATURE}

A surface area of layer, $\mathrm{m}^{2}$

$\mathrm{C}_{\mathrm{p}}$ steel specific heat at constant pressure, $\mathrm{J} /(\mathrm{kg} . \mathrm{K})$

D billet diameter, $\mathrm{m}$

E dimensionless error

h heat transfer coefficient, $\mathrm{W} /\left(\mathrm{m}^{2} . \mathrm{K}\right)$

$\mathrm{K}$ thermal conductivity, W/ (m.K)

$m$ mass of a layer, $\mathrm{kg}$

$\overline{\mathrm{NU}}$ dimensionless mean value of Nusselt number

Pr dimensionless value of Prandtl number

$\mathrm{Ra}$ dimensionless value of Rayleigth number

re external radius, $\mathrm{m}$

ri internal radius, $\mathrm{m}$

$\mathrm{T} \quad$ layer temperature, $\mathrm{K}$

$\mathrm{t}$ time, $\mathrm{s}$

\section{Greek symbols}

D difference between values of a property

$\varepsilon \quad$ dimensionless steel emissivity

$\sigma \quad$ constant of Stefan Boltzmann, W/ $\left(\mathrm{m}^{2} . \mathrm{k}^{4}\right)$

\section{Subscripts}

$\begin{array}{ll}\text { conv } & \text { convection } \\ \mathrm{n} & \text { layer index } \\ \mathrm{p} & \text { iteration index } \\ \mathrm{rad} & \text { radiation } \\ \infty & \text { environment }\end{array}$

\section{INTRODUCTION}

The seamless tube production process has as its first step the heating of steel billet at a temperature of about $1200^{\circ} \mathrm{C}$, after heating these billets are transported to the rolling mill. The temperature that the billet reaches the rolling mill is of great importance for the process quality. Thus, in order to understand and predict the cooling process during the transport, the heat transfer present in the cooling processes was studied and mathematically modelled. A tool was developed to simulate the cooling profile during transport. The cooling profile was determined using energy balances performed on the billet, and these were numerically solved using the technique of successive substitutions (Chapra 2004). To validate the results, measurements were made with thermocouples (billets of 270, 230 and $180 \mathrm{~mm}$ in diameter).

The knowledge of the cooling mechanism allows determining the cooling profile, the minimum unloading temperature and the maximum transportation time, it also allows a more efficient setup of the equipment, so generating a reduction in production costs and improving de product quality.

\section{MATHEMATICAL MODEL}

In the mathematical model, the one-dimensional cooling (radial direction) was considered, and only the central section of the billet was analyzed, so the 
edge effect present at the extremities was not considered. Once this was defined, the section was divided into $\mathrm{n}$ layers. The surface layer (layer 1) exchanges heat by radiation and natural convection with the external environment, and exchange heat by conduction with layer 2 . The internal layers (2 to n-1) exchange heat through conduction. The last internal layer (n) has very small area, close to zero, so it is considered that the temperature of this layer is equal to that of layer n-1. Figures 1 and 2 illustrate theses heat exchanges.

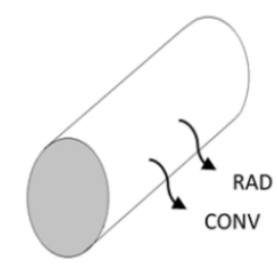

Figure 1. Heat Transfer Surface Layer.

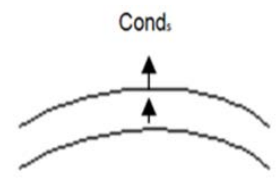

Cond.

Figure 2. Heat Transfer Layer 2 to n-1.

\section{ENERGY BALANCE}

According to (Incropera et al. 2014), the energy balance can be solved in a discrete way for each layer, approaching $d T / d t$ by $\Delta T / \Delta t$. The time step, $\Delta \mathrm{t}$, is equal to $1 \mathrm{~s}$, temperature and dependent properties (Cp, $\mathrm{h}_{\text {conv }}, \mathrm{h}_{\mathrm{rad}}$, and $\mathrm{k}$ ) were updated every iteration.

$$
\begin{array}{r}
\text { m.Cp. } \frac{\Delta T}{\Delta t}=h_{\text {conv }} \cdot A\left(T-T_{\infty}\right)+h_{\text {rad }} \cdot A\left(T-T_{\infty}\right) \\
=+k \cdot \frac{2 \pi}{\operatorname{Ln} \frac{r e}{r i}} \cdot\left(T_{n}-T_{n+1}\right)
\end{array}
$$

where: $m$ is the mass of a layer, $\mathrm{kg}$; $C \mathrm{p}$ is the specific heat of the steel, $\mathrm{J} /(\mathrm{kg} . \mathrm{K}) ; \mathrm{T}$ is the layer temperature, $\mathrm{K} ; t$ is time, $\mathrm{s} ; h_{\text {conv }}$ is the convective heat transfer coefficient, $\mathrm{W} /\left(\mathrm{m}^{2} . \mathrm{K}\right) ; A$ is the surface area of layer, $\mathrm{m}^{2}, h_{\text {rad }}$ is the coefficient of heat transfer by radiation, $\mathrm{W} /\left(\mathrm{m}^{2} . \mathrm{K}\right)$; re is external radius, $\mathrm{m}$; ri is internal radius, $\mathrm{m}$; $\mathrm{n}$ is the layer index.

The equation of the layer 1 (surface layer) is given by Eq. (1).

$$
\begin{gathered}
h_{\text {rad }}=\varepsilon \cdot \sigma \cdot\left(T_{n}+T_{\infty}\right) \cdot\left(\mathrm{T}_{n}^{2}+T_{\infty}\right) \\
h_{\text {conv }}=\frac{\overline{N U} \cdot K}{D}
\end{gathered}
$$

where: $\varepsilon$ is the dimensionless emissivity of the surface of the steel billets (equal to 0.91); $\sigma$ is the constant of Stefan Boltzmann, $\mathrm{W} /\left(\mathrm{m}^{2} . \mathrm{k}^{4}\right)$; $\overline{\mathrm{NU}}$ is the dimensionless mean value of the Nusselt number of the billet; $k$ is the thermal conductivity, $\mathrm{W} /(\mathrm{m} . \mathrm{K})$; D is the diameter, $\mathrm{m}$.

Eqs. (2) - (3) represent the heat transfer coefficients by radiation and convection respectively.

$$
\overline{N U}=\left\{0.60+\frac{0.387 \cdot R a^{\frac{1}{6}}}{\left[1+\left(\frac{0.559}{\operatorname{Pr}}\right)^{\frac{9}{16}}\right]^{\frac{8}{27}}}\right\}^{2}
$$

where: $\mathrm{Ra}$ is dimensionless numbers of Rayleigth; Pr is dimensionless number of Prandtl.

According to Churchill e Chu (1975), Nusselt along the surface, can be estimated for numbers of Rayleigth less than 1012 as in Eq. (4).

$$
\begin{gathered}
m \cdot c_{p} \cdot \frac{\Delta T}{\Delta t}=k \cdot \frac{2 \pi}{\operatorname{Ln} \frac{r e}{r i}} \cdot\left(\mathrm{T}_{n}+T_{n+1}\right) \\
\mathrm{T}_{n}=T_{n-1}
\end{gathered}
$$

Eqs. (5) - (6) represent the energy balance for layers 2 to $n-1$ (inner layers) and layer $n$ (inner most layer).

\section{NUMERICAL METHOD}

In the energy balance equation Eq. (1), temperature is function of $h_{\text {conv }}$ and $h_{\text {rad }}$, which, in turn, are also function the temperature.

$$
T=f_{T}
$$

In order to solve the equation it was necessary an iterative method, in this case the technique of successive substitutions, where temperature is calculated exclusively in function the temperature, as in Eq. (7) (Chapra 2004). To implement this method and solve the equations was written a code in $\mathrm{c}++$.

To accelerate the convergence of the method, the value found in the previous iteration was arbitrated as the initial temperature value.

$$
\left|\frac{T_{P}-T_{p-1}}{T_{p}}\right| \leq E
$$


where: $\mathrm{E}$ is the dimensionless error (equal to 0.01); $\mathrm{p}$ is iteration index.

The criterion of convergence of the method is given by Eq. (8).

Figure 3 illustrates the iteration process:

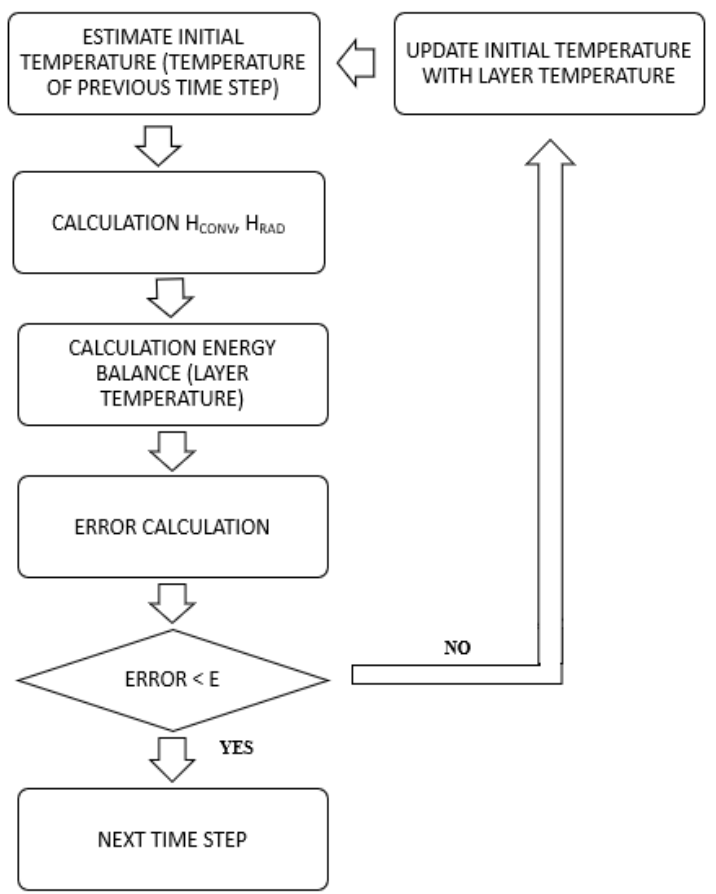

Figure 3. Iteration Process.

\section{MEASUREMENT WITH THERMOCOUPLES}

Measurements with thermocouples consist of using pre-instrumented billets with thermocouples type K, these are connected to a logger housed inside a thermal barrier, which function is to protect the logger from high temperatures. After being instrumented the billet is then load, heated, unload and transported to the entrance of the rolling mill. The logger records the temperatures at predetermined time intervals which allows filtering only the range of interest, in this case the time between the furnace exit and the rolling mill entrance. Once this is done, is possible to compare the measured and calculated cooling profiles.

The billet is instrumented with 10 thermocouples. Those of numbers $1,4,7$ are fixed to a depth of $10 \mathrm{~mm}$ from the upper face. Those of numbers 2, 5, 8 are fixed in the center. Those of numbers 3, 6, 9 are fixed to a depth of $10 \mathrm{~mm}$ from the lower face of the billet. The number 10 is not connected to the billet and works as an "antenna", recording the ambient temperature. The thermocouples are distributed in groups of 3 as showed in Fig.4. In this way measurements are made of the upper, lower faces and center in three regions of the billet.

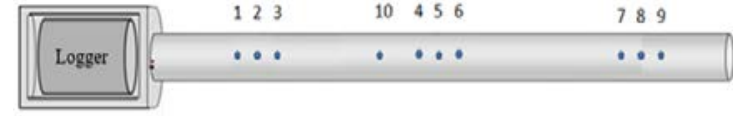

Figure 4. Instrumented Billet.

\section{RESULTS}

All the equipment used in the data collection were calibrated. The temperature profile of the billet during the cooling was simulated and can be compared to the profile measured with the thermocouples. The simulated temperature for the layer 2, which corresponds to the depth at which the thermocouple was fixed $(10 \mathrm{~mm})$, was used for analysis. The initial temperature value used in the simulation corresponds to the actual value of the thermocouple measurements at the start of the cooling. The cooling profiles for the three measured diameters (270, 230, $180 \mathrm{~mm})$ are showed in Fig.5, Fig.6, Fig.7.

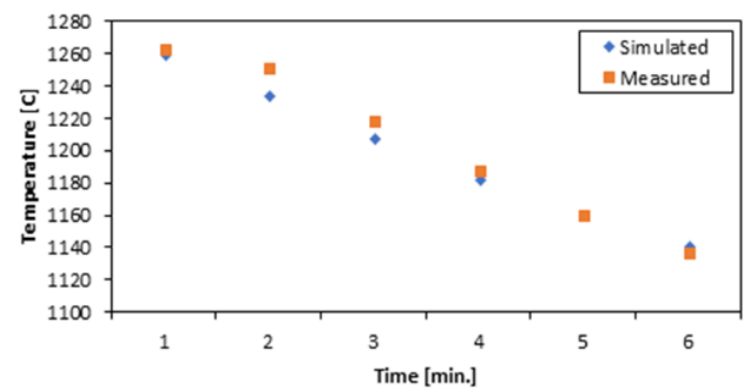

Figure 5. Cooling Profile Billet $270 \mathrm{~mm}$.

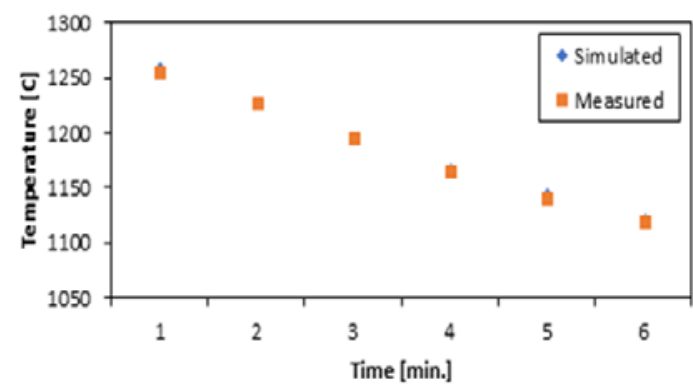

Figure 6. Cooling Profile Billet $230 \mathrm{~mm}$.

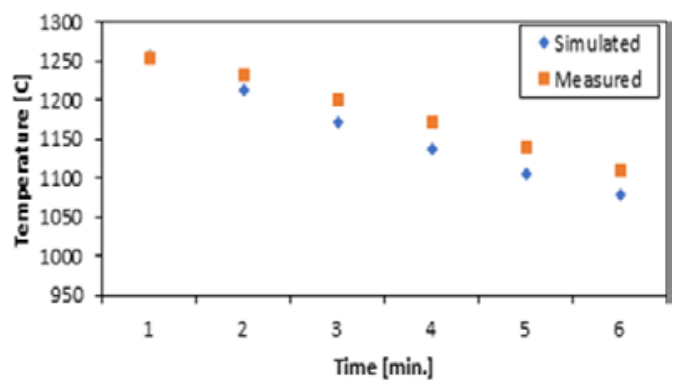

Figure 7. Cooling Profile Billet $180 \mathrm{~mm}$. 
The exact temperature measurements and simulations for the three diameters $(270,230,180$ $\mathrm{mm}$ ) are presented in Tab.1, Tab.2, Tab.3:

Table 1. Simulated and measured temperature values for $270 \mathrm{~mm}$ billets.

\begin{tabular}{|c|c|c|c|c|c|c|}
\hline & $\begin{array}{c}0 \\
\text { min. }\end{array}$ & $\begin{array}{c}1 \\
\text { min. }\end{array}$ & $\begin{array}{c}2 \\
\text { min. }\end{array}$ & $\begin{array}{c}3 \\
\text { min. }\end{array}$ & $\begin{array}{c}4 \\
\text { min. }\end{array}$ & $\begin{array}{c}5 \\
\text { min. }\end{array}$ \\
\hline $\begin{array}{c}\text { Simulated } \\
\text { Temperature [C] }\end{array}$ & $\begin{array}{c}125 \\
8\end{array}$ & $\begin{array}{c}121 \\
5\end{array}$ & $\begin{array}{c}117 \\
5\end{array}$ & $\begin{array}{c}114 \\
0\end{array}$ & $\begin{array}{c}110 \\
9\end{array}$ & $\begin{array}{c}108 \\
1\end{array}$ \\
\hline $\begin{array}{c}\text { Measured } \\
\text { Temperature [C] }\end{array}$ & $\begin{array}{c}125 \\
8\end{array}$ & $\begin{array}{c}123 \\
4\end{array}$ & $\begin{array}{c}120 \\
4\end{array}$ & $\begin{array}{c}117 \\
3\end{array}$ & $\begin{array}{c}114 \\
3\end{array}$ & $\begin{array}{c}111 \\
4\end{array}$ \\
\hline
\end{tabular}

Table 2. Simulated and measured temperature values for $230 \mathrm{~mm}$ billets.

\begin{tabular}{|c|c|c|c|c|c|c|}
\hline & $\begin{array}{c}0 \\
\text { min. }\end{array}$ & $\begin{array}{c}1 \\
\text { min. }\end{array}$ & $\begin{array}{c}2 \\
\text { min. }\end{array}$ & $\begin{array}{c}3 \\
\text { min. }\end{array}$ & $\begin{array}{c}4 \\
\text { min. }\end{array}$ & $\begin{array}{c}5 \\
\text { min. }\end{array}$ \\
\hline $\begin{array}{c}\text { Simulated } \\
\text { Temperature [C] }\end{array}$ & 1257 & 1229 & 1175 & 1169 & 1145 & 1122 \\
\hline $\begin{array}{c}\text { Measured } \\
\text { Temperature [C] }\end{array}$ & 1257 & 1238 & 1196 & 1167 & 1142 & 1121 \\
\hline
\end{tabular}

Table 3. Simulated and measured temperature values for $180 \mathrm{~mm}$ billets.

\begin{tabular}{|c|c|c|c|c|c|c|}
\hline & $\begin{array}{c}0 \\
\text { min. }\end{array}$ & $\begin{array}{c}1 \\
\text { min. }\end{array}$ & $\begin{array}{c}2 \\
\text { min. }\end{array}$ & $\begin{array}{c}3 \\
\text { min. }\end{array}$ & $\begin{array}{c}4 \\
\text { min. }\end{array}$ & $\begin{array}{c}5 \\
\text { min. }\end{array}$ \\
\hline $\begin{array}{c}\text { Simulated } \\
\text { Temperature [C] }\end{array}$ & 1263 & 1235 & 1208 & 1183 & 1161 & 1141 \\
\hline $\begin{array}{c}\text { Measured } \\
\text { Temperature [C] }\end{array}$ & 1263 & 1252 & 1219 & 1188 & 1161 & 1137 \\
\hline
\end{tabular}

$$
\text { Relative_error }=\frac{\mathrm{V}_{\text {measured }}-V_{\text {simulated }}}{\mathrm{V}_{\text {measured }}}
$$

The relative error between the simulation and the experimental data was calculated as in Eq. (9).

The calculated error values for the three diameters analyzed are presented in Tab. 4.

Table 4. Simulation Error in Relation to thermocouple Measurements.

\begin{tabular}{|c|c|c|c|c|c|c|}
\hline & $\begin{array}{c}0 \\
\text { min. }\end{array}$ & $\begin{array}{c}1 \\
\text { min. }\end{array}$ & $\begin{array}{c}2 \\
\text { min. }\end{array}$ & $\begin{array}{c}3 \\
\text { min. }\end{array}$ & $\begin{array}{c}4 \\
\text { min. }\end{array}$ & $\begin{array}{c}5 \\
\text { min. }\end{array}$ \\
\hline $270 \mathrm{~mm}$ & - & $1.36 \%$ & $0.90 \%$ & $0.42 \%$ & $0.00 \%$ & $0.35 \%$ \\
\hline $230 \mathrm{~mm}$ & - & $0.08 \%$ & $0.08 \%$ & $0.17 \%$ & $0.26 \%$ & $0.09 \%$ \\
\hline $180 \mathrm{~mm}$ & - & $1.54 \%$ & $2.41 \%$ & $2.81 \%$ & $2.97 \%$ & $2.96 \%$ \\
\hline
\end{tabular}

Table 5 presents the calculated average error values for the three diameters analyzed.

Table 1. Average error between Thermocouple Measurements.

\begin{tabular}{|c|c|}
\hline & Average Error \\
\hline $270 \mathrm{~mm}$ & $0.51 \%$ \\
\hline $230 \mathrm{~mm}$ & $0.11 \%$ \\
\hline $180 \mathrm{~mm}$ & $2.12 \%$ \\
\hline
\end{tabular}

\section{CONCLUSION}

This work achieved its objectiveof simulatethe cooling profile of the billets in the transport between the exit of the furnace and the entrance of the mill.
The understanding of this cooling allows the correct setup of the equipment, improving the quality of the tubesand reducing the costs with: rework; energy in the unnecessary heating of the billets; energy in the lamination of cold billets; premature wear of tools.

In general, the cooling model showed good accuracy, obtaining an average error of less than $2.5 \%$. In this way, it has satisfactorily allowing the use to help decision making in the industrial environment.

The model results for the billets of 270 and 230 $\mathrm{mm}$ presented a relative error lower than $0.5 \%$ indicating a good precision of the model. The results for the billets of $180 \mathrm{~mm}$ the simulation presented a relative error of approximately $2.12 \%$, being this, the worst result among the three types of billets studied. The reason for this being observed only in the 180 $\mathrm{mm}$ billet is that the production line of this billet is different from the 230 and $270 \mathrm{~mm}$ billets. Thus, the configuration of these equipment can influence the model boundary conditions, which were studied for the production line of billets of 270 and $230 \mathrm{~mm}$. A more detailed study is needed to refine the model for the production line of the $180 \mathrm{~mm}$ billets. However, the error is within the operating limit accepted and the model can be considered validated for use in the three billet diameters.

\section{ACKNOWLEDGEMENTS}

To Vallourec Soluções Tubulares do Brasil, CAPES, CNPQ and FAPEMIG for promoting research and development work.

\section{REFERENCES}

Chapra, S. C., 2004, Applied Numerical Methods with MATLAB, McGraw-Hill Book Company.

Churchill, S. W., and Chu, H. H. S., 1975, Correlating Equations for Laminar and Turbulent Free Convection from a Horizontal Cylinder, International Journal of Heat and Mass Transfer, Vol. 18, No. 9, pp. 1049-1053.

Incropera, F. P., Dewitt, D. P., Bergman, T. L., and Adriennes, L. S., 2014, Fundamentos de Transferência de Calor e de Massa, LTC Company book. (in Portuguese) 